PEDRO ÁlVAREZ CASELLI

ESCUELA DE DISEÑO

FACULTAD DE ARQUITECTURA, DISEÑO,

ESTUDIOS URBANOS Y TERRITORIALES

PONTIFICIA UNIVERSIDAD CATÓLICA

SANTIAGO, CHILE

PEDAL@UC.CL
1. Estudio realizado a partir de un corpus aproximado de 100 imágenes.

Fecha de recepción: 26/09/2017

Fecha de aceptación: 31/10/2017

Cómo citar: Álvarez Caselli, P. (2017). Post cartel

en Chile: la pérdida del aura y su devaluación en tiempos de Google. De la realidad exclusiva a la virtualidad inclusiva. RChD: creación y pensamiento, 2(3), 1-11.

DOI: 10.5354/0719-837X.2017.47700

\section{Post cartel en Chile: la pérdida del aura y su devaluación en tiempos de Google}

\author{
Post poster in Chile: The loss of the aura and its devaluation \\ in the Google Era.
}

Resumen. El presente texto, desde una perspectiva cualitativa, analiza la circulación de carteles (en formato impreso y digital), principalmente vinculados a la esfera del espectáculo, el entretenimiento y la cultura en el contexto nacional reciente ${ }^{1}$, por medio de una discusión bibliográfica. Tiene como objetivo documentar, analizar y abrir un debate respecto del actual estatuto de la producción de carteles en un escenario donde nuestra subjetividad se ha ampliado en razón de un profundo cambio en los modos de producción y circulación de esta herramienta de comunicación, cuestionando la autonomía del diseñador. Se busca profundizar en una zona de investigación en la cual el cartel ha tenido una suerte de discontinuidad histórica que actualmente se torna aún más compleja dada su proliferación y presencia, tanto en el espacio urbano como en redes sociales digitales. El artículo en cuestión remite a un despliegue de artefactos culturales híbridos, inmediatos, transitorios e incluso kitsch, que son testimonio de la mentalidad de una época concreta.

Palabras clave: autodiseño, cartel chileno, dimensión aurática, kitsch, softwares de edición gráfica.

\begin{abstract}
The present text analyzes the circulation of posters (in print and digital formats), mainly related to the show sphere, to entertainment and to culture in the national recent context. It is aimed at keeping records, analyzing and opening a debate in respect to the present statute of the production of posters, in a scene where our subjectivity has been extended due to a profound change in the ways of production and circulation of this communication tool, questioning the designer's autonomy. It seeks to deepen in a research area, in which the poster has been somehow historically discontinued, and at present it becomes more complex, due to its proliferation and its presence in the urban area as well as in the digital social networks. The document concerned is referred to a deployment of hybrid cultural devices, which are temporary or even kitsch. They are an evidence in the spirit of a definite age.
\end{abstract}

Keywords: algorithmic dimension, aural dimension, chilean poster, kitsch, self design.

Revista Chilena de Diseño,

RChD: creación y pensamiento

Universidad de Chile

2017, 2(3)

http://rchd.uchile.cl 
2. Para este artículo se opta por la noción de

"cartel", como expresión española, en vez de "afiche", en tanto derivación del galicismo affiche.

3. Conectada fundamentalmente a la tradición, el aura constituye un aspecto incidental de un objeto o de un acontecimiento, derivado de su valor de uso o de su relación directa con la producción: normalmente manufacturados o producidos en los momentos iniciales de la industrialización, los objetos aureáticos conservan la huella de las manos que les dieron vida [...] Con la reproducción en masa el aura sobrevivió como algo fragmentario y disperso que ya no se encontraba unido exclusivamente a un objeto esencial y auténtico (Olalquiaga, 2007, p. 17).

\section{Introducción}

La presencia del cartel ${ }^{2}$ en Chile, en tanto herramienta de comunicación visual, no se ha manifestado como un fenómeno con una tradición local continua; más bien ha respondido a ciertas coyunturas históricas y procesos político-sociales que han determinado, de alguna forma, una producción particular asociada a ciertos momentos clave: los inicios de la Editorial ZigZag y las revistas ilustradas de principios del siglo veinte (Noticias Gráficas, Chile Ilustrado, La Lira Chilena, etc.); las iniciativas Ilevadas a cabo por la Universidad de Chile canalizadas a través del impulso de los concursos de carteles organizados con motivo de las Fiestas de la Primavera y el empuje de la Escuela de Artes Aplicadas, que significó la emergencia de ciertos artífices y cartelistas (Nicolás Martínez, Fernando Ibarra, Marcial Lema, Julio Bórquez, Luis Troncoso, Santiago Nattino, etc.); la transición del gobierno de Frei al de Allende, que apuntaló una vasta producción de carteles de carácter cultural y político -casos concretos de Vicente Larrea y Waldo González-, y una suerte de reacción espontánea desde el primer gobierno de Michelle Bachelet frente a problemas actuales de difícil solución como el acceso a la educación gratuita, el sistema de pensiones y la asistencia a los problemas de salud. Asimismo, se ha desarrollado una vasta producción en torno a fenómenos ligados a los eventos culturales, políticos y sociales. De esta última instancia, se desprende un corolario de imágenes que han lindado con el formato del cartel, cuya difusión ha rondado entre paredes de ciertos sectores céntricos de la capital y provincias (en formato fotocopia, serigrafía instantánea o impresión offset o digital) y al mismo tiempo circulado en redes sociales digitales como producto transmutado en una imagen conformada por pixeles y algoritmos.

\section{El cartel: supervivencia en la acomodación a nuevos formatos}

Podemos iniciar la discusión con una simple pregunta: ¿Es posible hablar de cartel chileno en tiempos en que la imagen se ha devaluado y, en buena medida, perdido su valor? Hace casi un siglo, autores de referencia como Walter Benjamin se cuestionaban este fenómeno a propósito de la incesante reproducción de las imágenes, que habían perdido su "aura"3 producto de la aparición de nuevos medios que permitían la serialización en copias idénticas a partir del diseño o el original (se refería, en concreto, a la fotografía) en tanto medio de reproducción de cualquier imagen que de alguna forma perdía su dimensión de obra única.

Reflexión tan lúcida como hoy obsoleta, la visión de Benjamin prefiguraba un asunto propio del siglo veintiuno: la pérdida de la experiencia o capacidad de asombro. Más adelante, el filósofo Giorgio Agamben advirtió que obtener una experiencia de algo significaba "quitarle su novedad, neutralizar su potencial de shock" (Agamben, 2004, p. 55). En rigor, una expropiación de la experiencia ante una infinidad de estímulos en medio de un "lugar común" en el cual primaba un proceso de acumulación de incentivos vinculados a la apariencia de las cosas. En este contexto, si el cartel decimonónico y del siglo veinte se impuso como acontecimiento auroral, fundamentando la conciencia de un nuevo horizonte del diseño, en estas últimas décadas se produjo un profundo cambio que, en palabras de Maurizio Vitta, supuso "el ocaso del cartel", donde el muro "ya no es aquel efervescente soporte de informaciones y el cartel que fue su vehículo, cada vez tiene menos razón de ser" (Vitta, 2003, p. 319). 


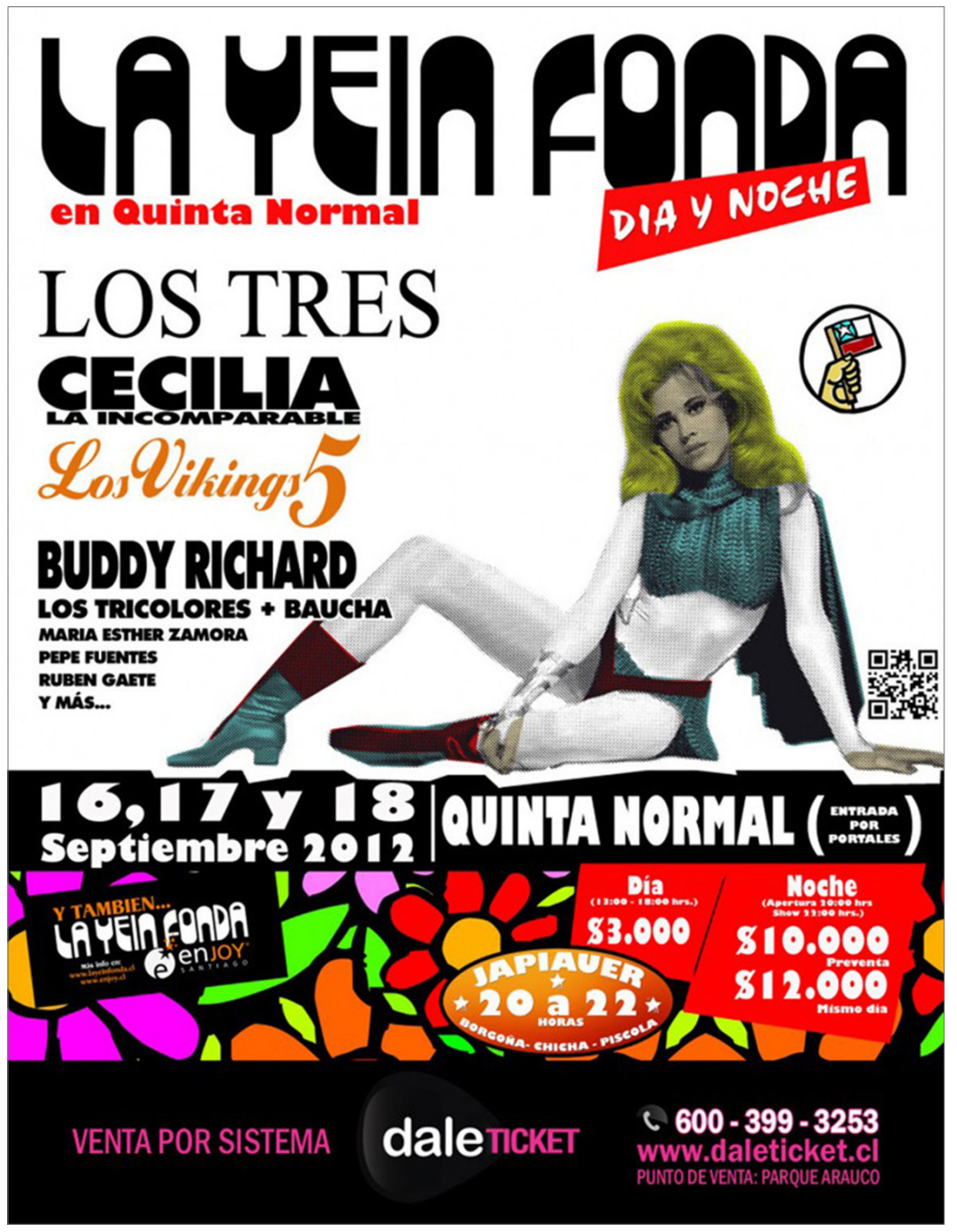

Aunque sea discutible la propuesta de Vitta, lo cierto es que diseñar un cartel antes de la llegada de los computadores personales, el proceso era bien distinto. En este sentido, este "invento capitalista", de acuerdo a lo planteado por Susan Sontag, nació como un instrumento social en el que era normativo comprar, transformándose en una suerte de "sustituto de la experiencia" (Sontag, 1999, p. 239). En esta aparente coincidencia con Agamben, la escritora presupone el concepto moderno de público (o usuario) donde el cartel opera como una eventual exigencia de atención ante un espectador o consumidor donde los elementos visuales predominan sobre el texto en una suerte de terreno de signos.

Quizás un aspecto interesante y anticipatorio que propuso Sontag, hace 47 años, es que los autores de carteles remitían en forma continua a la "cita" e incluso al plagio (de sí mismo o de otros), en tanto "uno de los principales rasgos de la historia de la estética del afiche y [...] tendencia estilísticamente parasitaria". (Sontag, 1999, p. 243). O, como bien advierte Susan Buck-Morss, cada vez que las modernas innovaciones aparecían en la historia moderna, "tomaban la forma de restituciones históricas. Las nuevas formas 'citaban' a las viejas fuera de contexto" (Buck-Morss, 2001, p. 129).
Figura 1. Cartel para la promoción de evento para celebrar las Fiestas Patrias, 2012. En el mismo, se observa la incorporación del código QR (Code Reader) que permite enlazar el cartel impreso bidimensional a un sitio web o URL (Uniform Resource Locator).

Fuente: <http://carretes.cl/2012/09/o6/la-yein-fonda-en-quinta-normal-16-17-y-18-de-septiembre> 
Figura 2. Cartel para espectáculo musical, 2010. Fuente: <https://marrasquino.wordpress.com/ page/2>

4. Se trataba, en aquel entonces, de una época compleja que intentaba restituir aquellos años felices de posguerra en los cuales se anunciaba la emergencia de este "grito en la pared", que implicaba abarcar todas las formas de vida y encontrar una visión popular que incitara a informarse o comprar un determinado producto o servicio.

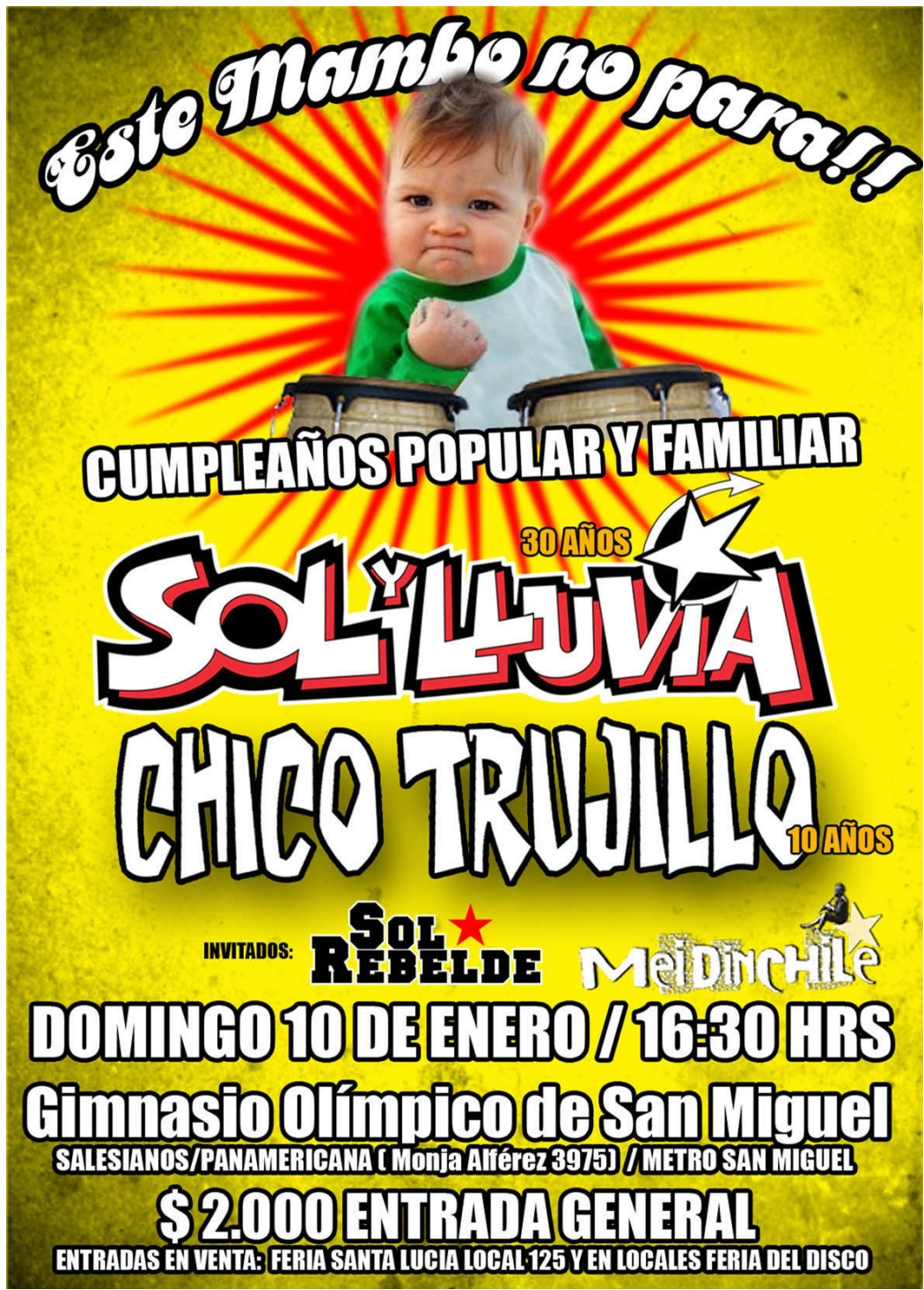

En atención a esta lógica, y retomando el quehacer reciente de los diseñadores, años atrás su actividad consistía principalmente en definir los parámetros sobre los que cajistas, fotomecánicos e impresores debían trabajar para conseguir el efecto proyectado (Llop, 2014, p. 17). Al producirse la expansión de la producción gráfica en el nuevo universo digital se generó un panorama de gran dispersión, e incluso de desregulación, en el cual aquellas destrezas y fortalezas propias del diseño gráfico validadas desde hace algunas décadas, comenzaron a atravesar por un cambio de procesamiento, principalmente respecto a su accesibilidad, consecuencia de la naturalización de la práctica apoyada por programas de edición gráfica hasta la dificultad de anticipar sobre qué soporte se visualizará un determinado mensaje gráfico -o un cartel- dada su actual doble militancia mediada entre el espacio público y el universo digital. Es decir, algo que ahora se mueve entre lo tangible y lo intangible, a diferencia de los carteles que definieron la modernidad del siglo veinte. ${ }^{4}$ 


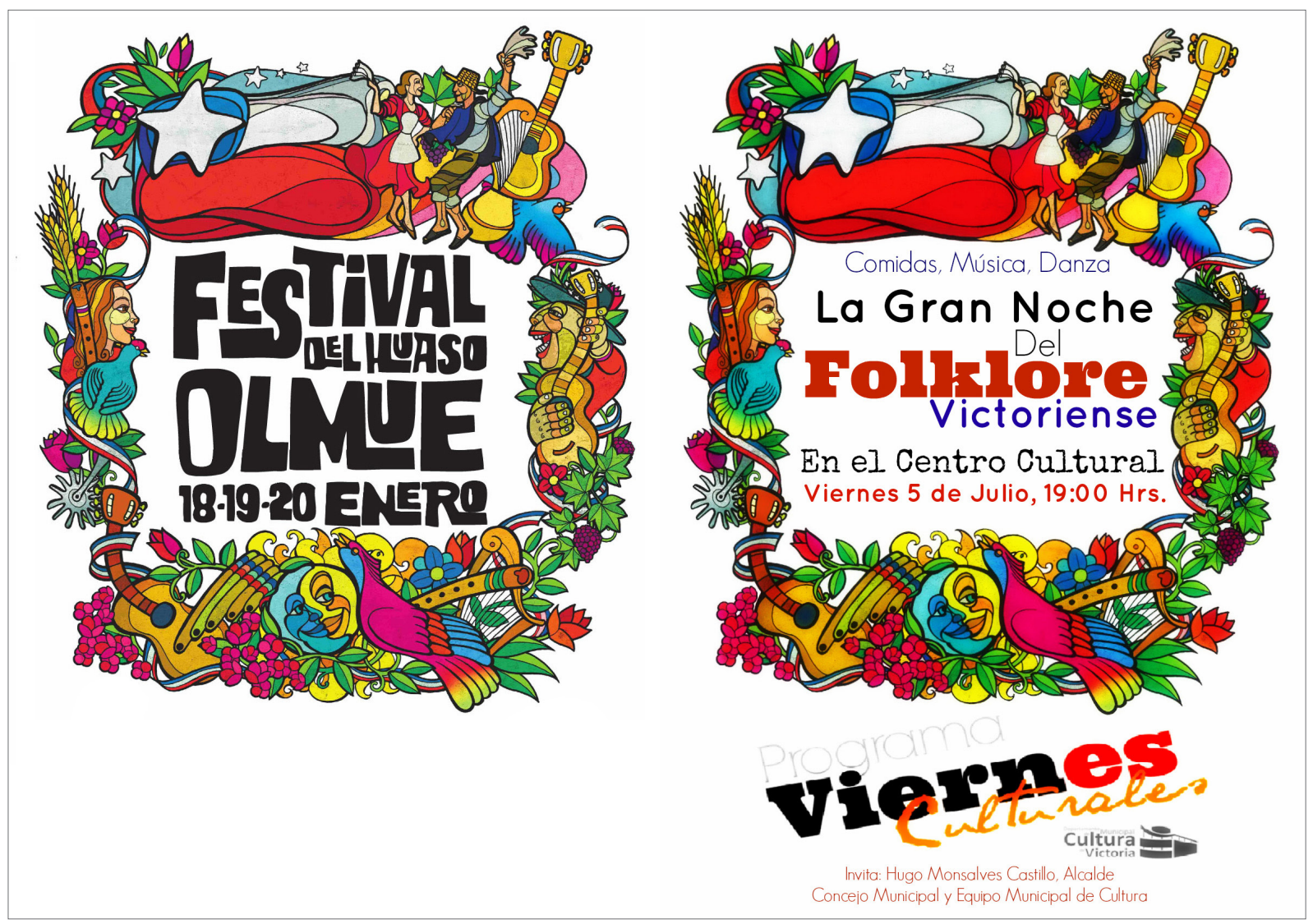

\section{Diseñarse uno mismo un cartel}

Actualmente, el escenario es bien distinto; la fragmentación de las variantes del cartel -que ya no requieren de una taxonomía basada en las tipologías definidas por los hoy nostálgicos axiomas de la modernidad o posmodernidad, o el estilo que se quiere combinar- está determinada por la prisa de la autoedición, vía impresión digital inmediata, en un sentido de domesticación frente a los procesos de automatización, aquello que expresa tangiblemente la inmediatez. De hecho, existe ya una oferta de servicios de autodiseño basada principalmente en el uso de plantillas, aunque estas no cumplan con los requisitos mínimos que todo diseño debería reclamar; a saber, dar respuesta a un problema concreto de forma personalizada que es, a la inversa, procesado por un sistema estandarizado con una posibilidad determinada, digitalmente, de elecciones. En fin, frente a esta suerte de estereotipación de la expresión gráfica, las plantillas operan como sustitutos contemporáneos del cartel, práctica que puede resultar perjudicial ya que el diseño de este tipo de artefactos gráficos ha determinado durante siglos la estética de la cultura: desde impresos sobre las atrocidades de la guerra hasta acontecimientos de menor urgencia como eventos artísticos o actividades relacionadas con el mundo de los negocios.

La revolución digital consiste en una suerte de "capa matemática" que media nuestra relación con el mundo, ampliando nuestras posibilidades de interacción merced al acceso a procesadores cada vez más poderosos, instancia que ha generado un profundo cambio ontológico y antropológico, traducido
Figura 3. Los vacíos legales respecto a la autoría (propiedad intelectual) y la apropiación indebida de imágenes que circulan en internet han permitido que el diseño profesional de carteles, en su versión digital, sea utilizado como recurso gratuito, en tanto forma de plagio, para la producción de nuevos carteles. El diseño original (izquierda) es de 2008 y se inspira en el estilo propio de las brigadas muralistas, como Ramona Parra, al tiempo que el texto interior remite al trabajo tipográfico manual desarrollado por la oficina de Vicente Larrea para el diseño de gráficas de discos para la Discoteca del Cantar Popular (DICAP). Fuente: <http://somosg.cl/tag/folclor> 
en una nueva condición híbrida y menos reflexiva respecto al fundamento que dio vida al cartel en el siglo veinte. Si bien los diseñadores siguen dependiendo de su creatividad (en parte) el trabajo manual, la destreza adquirida en la práctica y la precisión en el trazo fino, entre otros factores, parecen haber quedado atrás. Ciertamente, los computadores y software de edición gráfica han transformado a los diseñadores y también a los manejadores de estos programas en sujetos algorítmicamente asistidos y ajustados a una "administración electrónica" de la vida (Sadin, 2017, p. 138).

En este sentido, siguiendo al diseñador mexicano Alejandro Tapia,

“mientras que los formatos analógicos presentan una gradación continua en la impresión de información -parecido al proceso de la percepción-, la transcripción digital es discontinua y procesa los datos a través de un código numérico. Ello ha traído como consecuencia que los formatos, los tipos, las retículas, los colores y las texturas sean fácilmente procesados y almacenados, que se puedan fragmentar o parcializar y que cualquiera de sus vectores estructurales pueda cruzarse con cualquier otro" (Tapia, 2004, p. 210).

Ante este frente tecnológico, como una instancia para mantener viva la tradición del cartel, ha prevalecido una nueva lógica para la producción de símbolos y signos y un nuevo tipo de reglas y redes para el intercambio cultural y la comunicación, ahora desafectada del clásico enunciado "emisor-receptor". La evidente matriz electrónica de los carteles proporciona un carácter más virtual e inmaterial, y también más efímero, lo que constituye una diferencia sustancial respecto a sus predecesores analógicos. La información así contenida es fácilmente desplazable, reproducible y modificable; ocupa poco espacio o un espacio mínimo y no pesa, con lo que hace que su transmisión sea prácticamente inmediata y que libere a la producción discursiva del volumen físico y material al que se encontraba sujeta (Tapia, 2004, p. 210).

\section{Desmaterialización de la autoría y los contenidos en el cartel}

La discusión entre "alta" y "baja" cultura es un tema ya zanjado desde hace varios años y ahora cabe preguntarse cuáles son los modos diferenciadores que permiten certificar la autonomía de los diseñadores gráficos, que desde el ámbito profesional o académico han validado la profesión mediante una producción particular y especializada en la generación de imágenes y comunicaciones visuales. Ello implica abordar el tránsito del quehacer del diseño gráfico desde la especificidad de una profesión basada en el manejo de destrezas manuales hacia una práctica mediada por softwares que preceden ciertas operaciones intangibles (Manzini, 1993, p, 182), donde los problemas de definición del diseño están a la vista -online- por tanto, la sabiduría de la disciplina se torna pública.

En 1997 se envió la primera fotografía desde un teléfono móvil (Fontcuberta, 2016, p. 21) y apenas veinte años han sido suficientes para desmantelar un régimen visual con un siglo y medio de duración; la revolución digital ha desmaterializado la autoría y también los contenidos para dar lugar a una suerte de "estética del acceso". En el momento actual, recibimos una gran cantidad de imágenes en formato digital en nuestra sección de correo electrónico a la par de un despliegue de carteles dispuestos en el espacio público que, en general, remiten a actividades políticas, culturales o vinculadas al mundo del entretenimiento. 


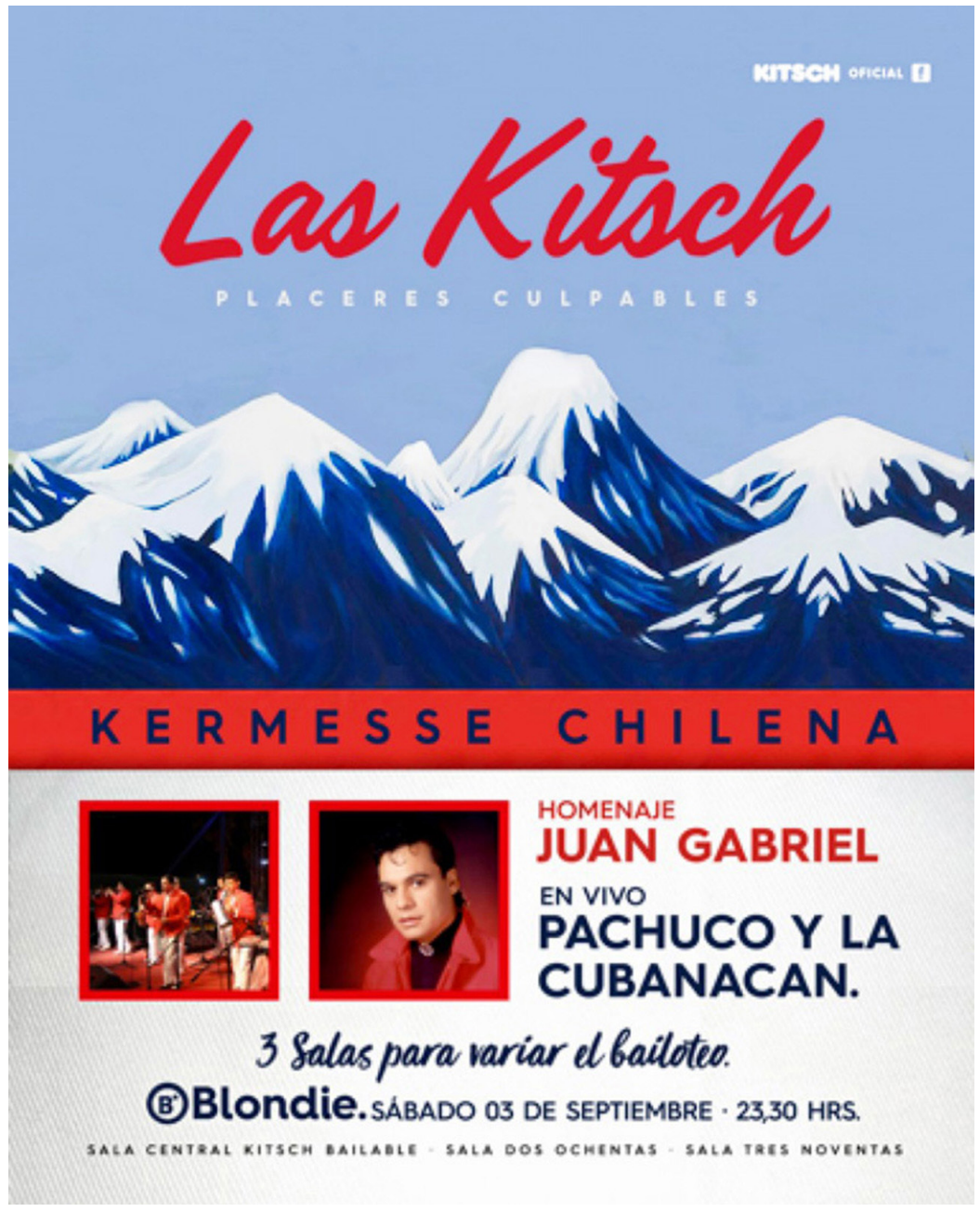

Buena parte de los carteles que circulan en Chile, impresos o digitales, son diseñados por personas que manejan ciertos programas como Photoshop o Illustrator -o versiones similares gratuitas-, generando una suerte de imaginario compartido y homogéneo producto del acceso a fuentes digitales extranjeras o de origen nacional (sobre todo, de inspiración vernacular) y a un repertorio de imágenes "pirateadas" o descargables de Google, incluso en una resolución baja, manipuladas por los recursos y efectos disponibles en los programas de edición gráfica comprados o "bajados" de internet.

Curiosamente, la consigna del "todo vale" impuesta durante el período histórico del diseño gráfico posmoderno, que coincidió con los primeros pasos de la era digital y el acceso reducido y privilegiado a computadores personales y softwares de alto costo con una serie de limitaciones técnicas, parece reproducirse ahora en una nueva versión de productores de imágenes y carteles que se desmarcan de las normas clásicas del diseño donde los límites entre aquello que tiene "cualidad de diseñado" o realizado de forma autodidacta y espontánea se tornan difusos.

En el cartel actual, masivo, prevalece su circulación por sobre su contenido o valor estético, cuyo nuevo estatus de imagen digital, antes solo impresa, genera una proliferación del mismo en computadores, tablets y teléfonos
Figura 4. Cartel para una kermesse, que alude al kitsch, en homenaje al cantante Juan Gabriel, organizada por la empresa de espectáculos Blondie, 2016. Aunque no tenga ninguna relación con el artista mexicano, el diseño recurre a una imagen canónica de la iconografía comercial chilena, que representa a la cordillera de los Andes utilizada como símbolo gráfico en uno de los productos más característicos de la Compañía Chilena de Fósforos.

Fuente: <http://www.blondie.cl/index.html> 
Figura 5. Cartel para promocionar la Fiesta del Borgoña, 2013. Se advierte el uso de fuentes digitales chilenas inspiradas en la gráfica popular (transporte urbano, fuentes de soda, "picadas", etc.), que en este caso adquieren una connotación diferente de la concebida para su uso original. Fuente: <http://clubmatadero.blogspot.cl/2013/12/ gran-fiesta-fin-de-ano-fiesta-del.html>

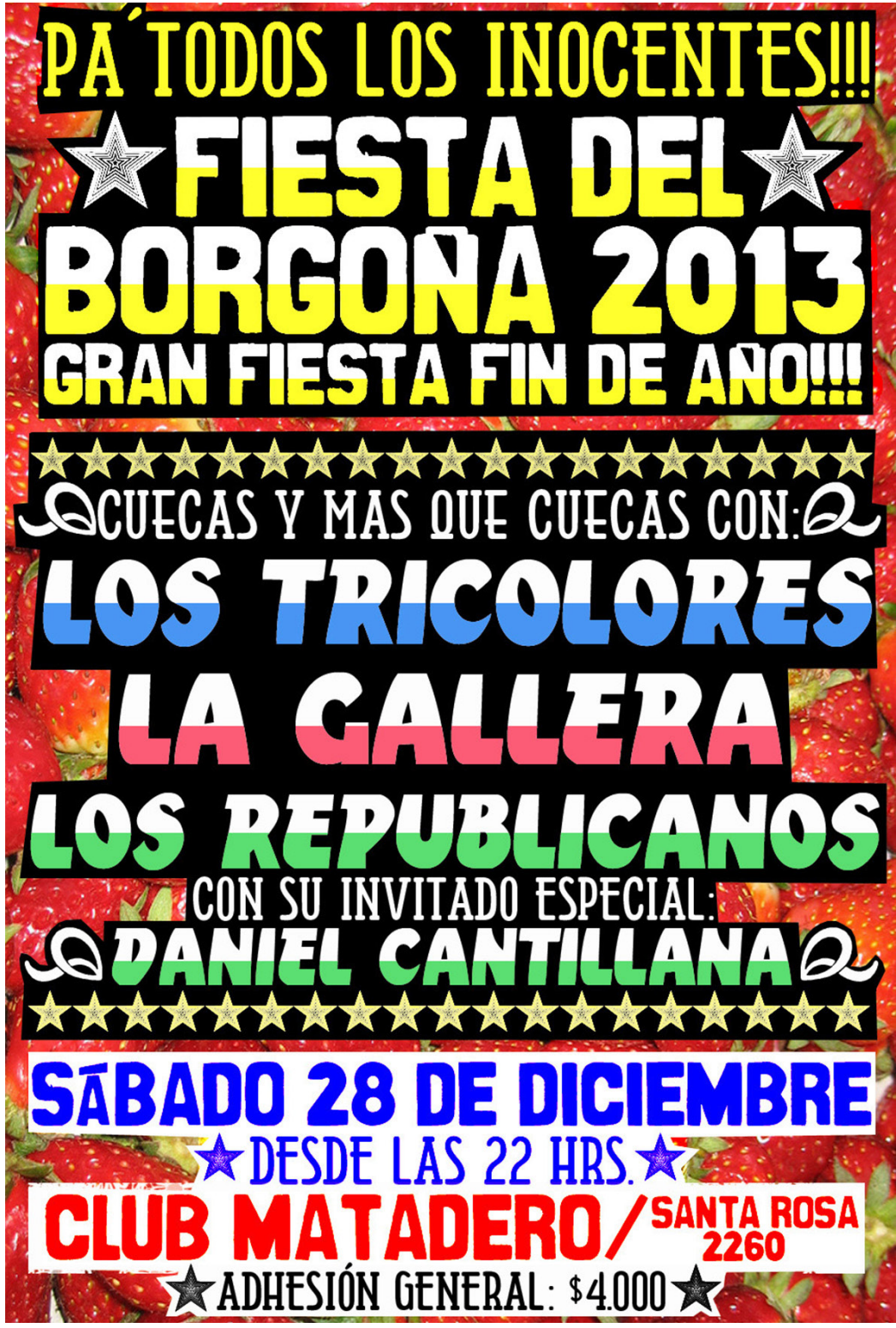

móviles que al saltar de pantalla en pantalla pierden el aura que les quedaba. El cambio en el procesamiento del cartel (impreso versus digital) ha tenido repercusiones no menores: antes se certificaba por su presencia real, ahora se ha dosificado esa particularidad entre su encuentro en una pared o un panel eléctrico urbano y su circulación en Google o redes sociales digitales en un momento en que la imagen constituye el espacio social de lo humano. Hace ya dos décadas, en el libro Primera colección Morgan. El afiche chileno, se planteaba que "si está bien hecho y resuelto -buen diseño-, un cartel o un afiche puede trascender como documento gráfico y memoria histórica de la cultura del buen diseño de un país" (Morgan, 1996, p. 3). En el nuevo régimen visual dominado por la proliferación de datos, cabe preguntarse si se puede recuperar su soberanía en tiempos donde el diseño vernacular o amateur de carteles supera ampliamente a la producción más cuidada y heredera del 


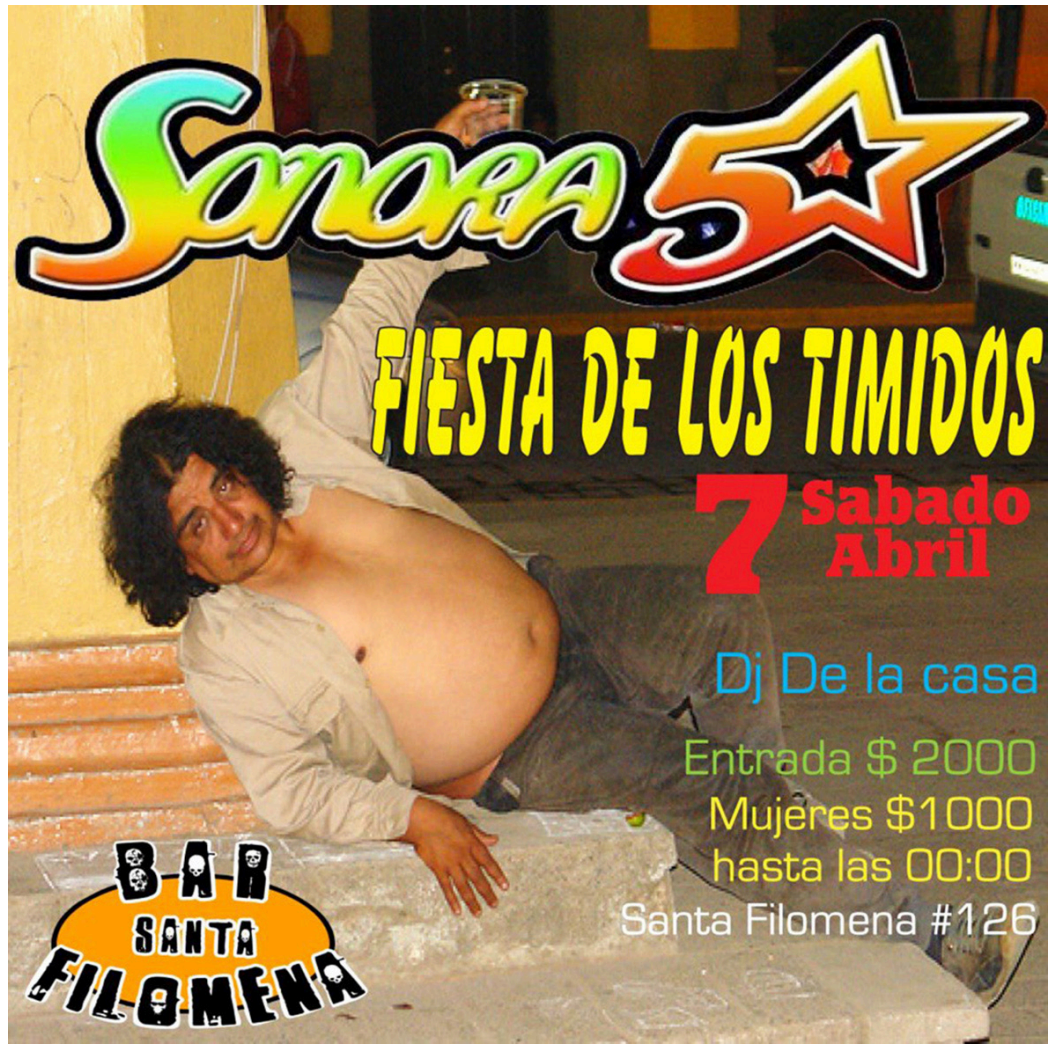

Figura 6. Cartel para promocionar a la Sonora 5 Estrellas, 2012. Si hay o no una ingenuidad estudiada en el mensaje, lo cierto es que la fotografía que opera como telón de fondo, capturada desde un dispositivo móvil o una cámara digital, refleja la posibilidad de hacer públicos los instantes más banales de nuestra vida y, de paso, cuestionar los cimientos de la fotografía publicitaria. Si antes cabía el deseo por la perfección en la elaboración y composición del cartel, este tipo de imagen vernacular se sitúa en la periferia de la esfera profesional.

Fuente: <https://afichesdecarretes.wordpress.com>

5. Por "buen diseño" remitimos a un concepto acuñado a mediados del siglo veinte para referirse a ciertos requerimientos particulares del diseño industrial y gráfico producido de forma masiva. Entre ellos, los requisitos de funcionalidad, simplicidad formal y adecuación de la forma a la función. Un objeto plenamente técnico que es solo signo de sí mismo. oficio del grafista que dominó en la escena nacional durante buena parte del siglo veinte. Se trata aquí de una producción cultural que podría localizarse fuera del ámbito del diseño profesional, en términos de su legitimación, que si bien se sitúa en la periferia de lo académico, supera cuantitativamente la producción del cartel artístico que responde a un "buen diseño".5 Ello se torna un reflejo de cómo las habilidades tradicionales en el manejo de dispositivos formales, el uso de tipografías con un criterio selectivo, o la capacidad intrínseca de generar imágenes, son hoy suplidas por los programas y algoritmos que despojan de un capital importante al diseñador.

\section{Post cartel}

Como acción de interés, resulta pertinente consignar que a este fenómeno se ha sumado, desde otro frente, la producción de carteles desde los movimientos estudiantiles. Aunque responden a distintas lógicas, hay una coincidencia en su inmediatez de producción, espontaneidad y circulación en redes sociales. Mientras en el cartel de eventos predomina la producción digital, en la avanzada estudiantil se han generado recursos como el trazado instantáneo y el uso de la serigrafía en una nueva clave política de reproducción de imágenes y discursos. En este sentido, y más allá de las posibles diferencias entre estas dos modalidades, esta nueva generación de carteles ha traído consigo un desprendimiento del capital de la disciplina -más como un ejecutor de sus propias configuraciones mentales que un interpretador y facilitador de la realidad en función de los otros- que abre una puerta a un nuevo sistema de producción y de evaluación de lo que es o no es un cartel, en tanto dispositivo heredero de la modernidad mecánica 
6. Cassandre fue el seudónimo de Adolphe

Jean-Marie Mouron, uno de los más destacados cartelistas de la primera mitad del siglo veinte, que consiguió sintetizar ideas y conceptos de la modernidad por medio de imágenes directas con una gran capacidad de retención.

7. Entrevista realizada por el autor en abril de 2013. y analógica que encumbró a autores como Alphonse Mucha, Cassandre o Roman Cieslewicz en paradigmas occidentales del diseño de autor en este tipo de soporte basado en la composición de texto e imagen en función de las limitaciones del formato impreso dominante.

En los actuales carteles chilenos de circulación anónima no interesa la cita, la referencia, la síntesis o la búsqueda de una cierta armonía compositiva; ahora prevalece una disposición aleatoria de imágenes y textos provenientes de distintos archivos digitales. No se trata de una crítica al modo de ejecución sino, más bien, del reconocimiento de una nueva modalidad de producción tan espontánea como desregulada y, en cierta forma, ligada a la mutación del hombre-masa al hombre-velocidad (Kerckhove, 1999, p. 95). Velocidad anunciada por Cassandre ${ }^{6}$ en sus ajustadas composiciones que en la actualidad prescinden de bocetos previos para conformarse como productos inmediatos que, como las fotografías digitales, se tornan desechables y pierden su valor-memoria una vez que ya han cumplido su función. Se trata de producciones exentas de prejuicios donde el uso de la fotografía instantánea o amateur, que pertenece a un ámbito íntimo o privado, ha desplazado a la calculada imagen publicitaria tradicional. Asimismo, el uso del texto -la tipografía descargable- aunque no demuestra un dominio formal o académico, se presenta de forma espontánea e incluso con un cierto nivel de autenticidad, cuestionando el "saber hacer" propio de la disciplina del diseño.

\section{Conclusión}

Hace unos años atrás, el grafista Waldo González señalaba que el cartelismo de antaño era una "batalla de lápices y pinceles".7 Aunque un sector vinculado a la producción de carteles desde la acción política, el activismo y las demandas estudiantiles ha propiciado un resurgimiento del cartel hecho a mano o impreso por medio de la técnica de la serigrafía, lo cierto es que la circulación de imágenes de origen digital como también la disposición de gigantografías en PVC en el espacio urbano ha tenido un fuerte predominio. Ello ha generado una coexistencia de variados repertorios que ya no responden a un estándar de referencia modulado sino a una dispersión de producciones efímeras en un sistema de libre mercado fragmentado en la era de la cultura en red. La "batalla", ahora, está mediada por algoritmos y pixeles que generan una suerte de visualidad homogénea e ingenua, donde prevalece el uso de recursos gratuitos disponibles online donde la noción de autoría se desintegra. Si bien pueden resultar formas de comunicación más vivas, o incluso auténticas, cabe preguntarse cuánto afecta esto al posicionamiento del diseñador y sus servicios en tanto déficit conceptual de la disciplina y falta de observación de sus propios lenguajes. 


\section{Referencias bibliográficas}

Álvarez, P. (2004). hDGch, Historia del Diseño Gráfico en Chile. Santiago: Pontificia Universidad Católica de Chile.

Agamben, G. (2004). Infancia e historia. Buenos Aires: Adriana Hidalgo Editora.

Buck-Morss, S. (2001). Dialéctica de la mirada. Walter Benjamin y el proyecto de los Pasajes. Madrid: La Balsa de la Medusa.

Castillo, E. (2004). Cartel chileno, 1963-1973. Santiago: Ediciones B.

Fontcuberta, J. (2016). La furia de las imágenes. Notas sobre la postfotografía. Barcelona: Galaxia Gutenberg.

Kerckhove, D. (1999). La piel de la cultura. Investigando la nueva realidad electrónica. Barcelona: Gedisa.

Llop, R. (2014). Un sistema gráfico para las cubiertas de libros. Hacia un lenguaje de parámetros. Barcelona: Gustavo Gili.

Manzini, E. (1993). La materia de la invención. Materiales y proyectos. Barcelona: Ediciones Ceac.

Martínez Sáez, J. (2015). Rock \& Love. Recetas para la supervivencia de la marcas en el s. XXI. Valencia: Campgràfic.

Morgan, J. P. (Dir.) (1996). Primera colección Morgan. El afiche chileno. Santiago: Morgan.

Olalquiaga, C. (2007). El reino artificial. Sobre la experiencia kitsch. Barcelona: Gustavo Gili.

Sadin, É. (2017). La humanidad aumentada. La administración digital del mundo. Buenos Aires: Caja Negra.

Sontag, S. (1999). El afiche: publicidad, arte, instrumento político, mercancía. En: M. Bierut, J. Helfand, S. Heller y R. Poynor, Fundamentos del Diseño Gráfico (pp. 239265). Buenos Aires: Infinito.

Tapia, A. (2004). El diseño gráfico en el espacio social. México: Designio.

Vico, M. (2013). El afiche político en Chile, 1970-2013. Santiago: Ocho Libros y Centro de Investigaciones Diego Barros Arana.

Vitta, M. (2003). El sistema de las imágenes. Estética de las representaciones cotidianas. Barcelona: Paidós. 